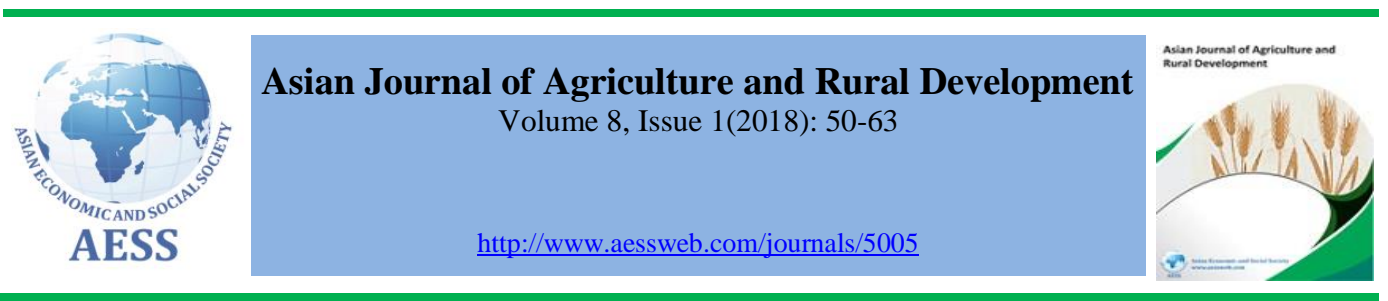

\title{
EVALUATING CONSTRAINTS TO ANIMAL TRACTION DEVELOPMENT AND SUSTAINABILITY IN THE UPPER NOUN VALLEY, NORTH WEST REGION CAMEROON
}

\section{Nuipokoh Oscar Mboungho ${ }^{\text {in }}$ \\ Manu Ibrahima \\ Dongmo Solefack ${ }^{b}$}

a Department of Agricultural Extension and Rural Sociology, Dschang University, Cameroon

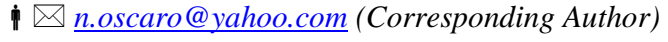

b Department of Agricultural Engineering, Dschang University, Cameroon

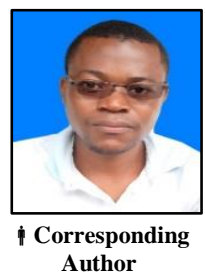

Author

\section{ARTICLE HISTORY:}

Received: 21-Aug-2018 Accepted: 29-Sep-2018 Online Available: $15-$-Oct2018

Keywords:

Animal traction,

Small-scale

Farmer,

Constraint

\begin{abstract}
The principal aim of this study was to find out the reasons for the low adoption of animal traction in the Upper Noun Valley community. The general views were; to find out the level of animal traction adoption, to see its level of profitability, to examine its importance on agricultural sustainability and the overall constraints and benefits involved in animal traction. Combinations of multi-stage random and purposive sampling procedures were applied to obtain the needed information from oxenfarmers and institutions. A cross sectional data was collected and analysed from random sample of 90 oxen farmers within the Upper Noun Valley Community. Data were collected and analysed using Statistical Package for Social Sciences (SPSS) and Microsoft Excel. The study revealed that smallscale farmers encountered several sustainability challenges from inappropriate implements, pasture difficulty, lack of training and repair centres, poor animal housing. Animal traction sustainability depends on its; affordability, flexibility, timeliness on farm and organic manure provision. In order to overcome the alarming food insecurity in Cameroon, both the government and stakeholders should regain consciousness on abandoned training centres, and minimum packages should be given to small-scale farmer as well as local blacksmiths and veterinary centres be provided at the Divisional level.
\end{abstract}

\section{Contribution/ Originality}

In the developing countries, low level of mechanisation and poor developmental policy are the main constraints to agriculture. Meanwhile, about $80 \%$ of farm family enterprises today depend on agriculture and cannot afford the cost of a modernised mechanisation system. Therefore, animal traction is a best solution looking at its comparative advantages though it faces some constraints in the Upper Noun Valley in Cameroon.

DOI: 10.18488/journal.1005/2018.8.1/1005.1.50.63

ISSN (P): 2304-1455/ISSN (E):2224-4433

How to cite: Nuipokoh Oscar Mboungho, Manu Ibrahim and Dongmo Solefack (2018). Evaluating Constraints to Animal Traction Development and Sustainability in the Upper Noun Valley, North West Region Cameroon. Asian Journal of Agriculture and Rural Development, 8(1), 50-63.

(C) 2018 Asian Economic and Social Society. All rights reserved. 


\section{INTRODUCTION}

Cameroon like most African countries is an agricultural economy with about $70 \%$ of her workforce involved in the agricultural sector with $45 \%$ of her GDP and 30\% of her export revenue (Johnston and Mellor, 2007). However, agriculture is one of the highest sectors in Cameroon to combat food insecurity to both the Cameroonian rural and urban populations.

Farming in the Upper Noun Valley is still one of hardest human work and involves the use of crude tools by the local farmers. Mechanisation is a step to second generation agriculture, therefore, animal traction technology is a step to encourage and enhance the growth of agricultural mechanisation geared toward second generation agriculture.

In 2003, according to the United Nations Food and Agriculture Organisation (FAO), only 35 per cent of farm power came from non-human power sources, indicating that there is a big potential for the use of mechanical farm power in the Sub-Saharan region (Nazaire et al., 2015). In response, agricultural mechanisation has re-emerged recently in many countries in Sub-Saharan African. In Cameroon, animal traction technology in the North West Region started locally in Ndop in 1968 and in Wum in 1969 and later spread to other Regions in 1980. Animal traction became a major extension program of the Wum Area Development Authority (Njei, 1987).

Cameroon cooperated with the German Government in 1985 in the creation of the Promotion of Adapted Farming Systems based on Animal Traction (PAFSAT), where small-scale farmers were being trained on how to use animal traction technology as a mechanised means of farming. PAFSAT had its principal objective on rural development with more emphasis laid on agricultural development aiming to improve the livelihood of the farmers (MIDENO, 2010). Coupled with numerous challenges like; inappropriate implements, pasture difficulty, lack of training and repair centres, poor animal's housing to animal theft and diseases, there is the need to harness draftcultivation for adequate farm-power supply, in order to develop the agricultural sector.

Umaru et al. (2013) on their part reviewed that animal traction has a significant interest to the rural farmers. To these people, animal are very important for carrying domestic water, fuel, farm produces and reducing drudgery most especially for women. Money invested in animal traction circulates within the rural communities as plough boys, blacksmith, carpenters, all found within the locality are considered as; "chain-actors". In Sokoto State Nigeria, most of the rural farmers are involved in animal traction as they used its power for milling, logging, and land evacuation.

A study was carried out in Tororo on the contribution of draft cattle to rural livelihood in a district of South-Eastern Uganda. This was to assess the socio-economic impact of animal traction on the inhabitants. This study shows that, animal draft cultivation is a labour saving and a cheaper means of agricultural mechanisation as an average farmer gets a gross profit margin of about 245 United State Dollar per year. It was concluded that, draft cultivation has contributed to a better livelihoods and increasing the expected impact of cost-effective control strategies of endemic production limiting livestock diseases in Uganda (Walter et al., 2015).

In Catabola, farmers are mostly using hand hoe. Small-scale farmer do use animal traction as well but for particular task. The use of animal traction is about 6.6\%. The low level of tractorisation and animal traction is due to poor literacy rate of the farmers. However, farmers using more advanced technologies for farming in this region are more efficient and have higher production than those with hand-hoe based (Rušarová et al., 2016).

\subsection{Problem statement}

The use of animals for agricultural purposes such as, ploughing, harrowing and weeding by a smallholder farmer who owns a very small plot of land is profitable and not economically viable for 
him to purchase a tractor. Animal traction simplifies daily tasks like; carrying water, firewood, farm produces, tilling, and weeding to ensure sustainability. The use of animal traction provides a complementary power option for agriculture but can be supplementary to the use of tractors. The use of animal traction is important because it serves time and its timeliness on farms is a gaining advantage to the small-scale farmers as they are able to cultivate on time regarding their farming period. Animal draft power increases productivity, reduces drudgery, and it also reduces farmers' rate of dependency on scared tractors and its equipment can be gotten locally and operated by the local farmers unlike the tractors that need know-how, fossil fuels, spare parts and maintenance which may not be available to the farmers at all times. Animal traction does not limit its importance on agriculture alone but also creates work opportunity as its uses can stimulate the development for artisan resources thereby keeping the blacksmiths, carpenters, leather-markers and even the ploughboys engaged. These animals are fed on crop residues and they can supply other produces like meat, milk, leather and manure for soil fertility and biogas to the farmers and the local population as a whole. Therefore, the development of animal draft cultivation in the Upper Noun Valley is a cause for concern. Although animal traction in Africa is a subject of considerable interest in terms of sustainable development, many writers have contributed to its technological aspects and values but little is said about the constraints of its development, sustainability and cost effectiveness. Animal traction is relatively a cheaper and an easier means for agricultural mechanisation and food security, yet it has not been well developed as oxen-farmers face numerous challenges like inappropriate implements, poor land tenancy, limited grazing space, poor animal's shades, theft and diseases in the country especially in the Upper Noun Valley.

\section{METHODOLOGY}

\subsection{Presentation of upper noun valley}

Ngoketunjia which is also known as the Upper Noun Valley is one of the Seven (07) Divisions of the North West Region of Cameroon that shares boundaries with Bui Division to the North, Mezam Division to the West, Bamboutos to the South and East respectively. It lies between latitude $5^{0}, 15^{1}$ $\mathrm{N}$ and $6^{0}, 10^{1}, \mathrm{~N}$ and longitude $10^{0} 15^{1} \mathrm{E}$ and $10^{0} 40^{1} \mathrm{E}$. The Upper Noun Valley has an altitude of about $1,181 \mathrm{~m}$ above sea level and covers a surface area of about $1,152 \mathrm{~km}^{2}$ with a population of about 254530 inhabitants (DDARD/Ng Annual Report, 2017).

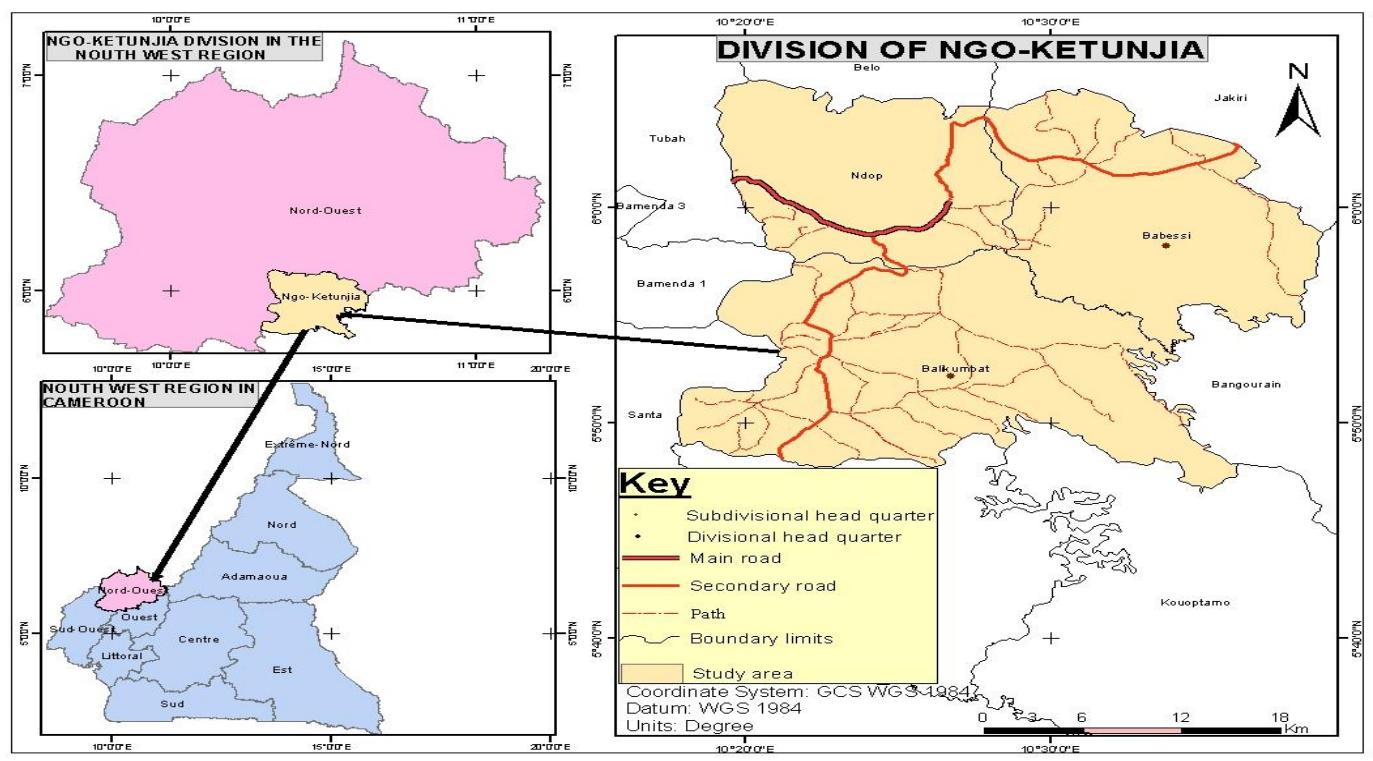

Figuer 1: Localisation of Ngokitunjia Division

Source: Nuipokoh, 2018 


\subsection{Data collection}

Primary data for this study was collected through direct survey, while the secondary data was collected from institutional reports like MIDENO, Divisional Delegation for Agriculture and Rural Development for Ngoketunjia and internet. The main survey was conducted in March 2018. A comprehensive questionnaire was used to obtain primary data, while secondary data was collected through direct individual interviews with the help of an interview guide. The purposive sampling method was used to come up with the sample from the sampled population. Sampling was based on those that were practicing and those still practicing animal traction technology. Collected data from the study was manually stripped, coded and after quality control entered into SPSS (Statistical Package for Social Sciences) Version 20 and Microsoft Excel software for statistical analysis.

\section{RESULTS AND DISCUSSIONS}

In the Upper Noun Valley (UNV), the study was conducted in four villages of; Bamessing, Bangolan, Babessi and Bamunka. The highest percentage of oxen-farmers was recorded in Bamessing and Bangolan respectively with least in Bamunka and Babessi respectively (Table 1). The $1.1 \%$ of animal traction engagement in Bamunka is due to: population pressure on land, urbanisation, the provision of tractorisation by the UNVDA, and unsuccessful diffusion of animal traction technology by the early adopters which led to the abandonment of animal traction implement by some pioneer oxen-users in Bamunka. Generally, the spread and adoption of animal traction technology over time in Ngoketunjia is due to behavioural change and awareness amongst the people. This trend ties with Roger's idea of innovation diffusion (Everett, 1971).

Table 1: Respondent's distribution

\begin{tabular}{lcc}
\hline Villages & Frequency & Percentage \\
\hline Bamessing & 40 & 44.4 \\
Bangolan & 31 & 34.4 \\
Babessi & 18 & 20.0 \\
Bamunka & 01 & 1.1 \\
Missing System Total & 90 & 100 \\
\hline
\end{tabular}

Table 2: Social description of respondents

\begin{tabular}{lcc}
\hline Variables & Frequency & Percentage \\
\hline Gender & 86 & 95.6 \\
Male & 4 & 4.4 \\
Female & & \\
Age & 1 & 1.1 \\
$<20$ & 5 & 5.6 \\
$20-29$ & 67 & 74.4 \\
$30-39$ & 9 & 10 \\
$40-49$ & 3 & 3.3 \\
$50-59$ & 5 & 5.6 \\
$60>$ & & \\
Marital status & 88 & 97.8 \\
Married & 2 & 2.2 \\
single & & \\
Households & 43 & 47.8 \\
$<5$ & 35 & 38.9 \\
$9-$ May & 12 & 13.3 \\
10> & 90 & 100 \\
Total & & \\
\hline
\end{tabular}


In regard to gender distribution, $95.6 \%$ were males while $4.40 \%$ of the sampled population were females (Table 2) Animal traction in the UNV has three principal activities which are; ploughing, harrowing and transportation which women considered being tedious, this accounts for the low involvement of women in this technology. Women however assist the men from time-to-time in weeding and feeding of the animals.

The highest proportion of oxen-users in UNV falls under the ages of 30-39 representing about $74.4 \%$. These locals take animal traction as a means of employment and a source of income. This age group is the most energetic and most vulnerable to unemployment and this accounts for their high engagement. Those below the ages of 29 are mostly students and are less represented as school enrolment has increased in the UNV. Due to scepticism, those between 40-49 years who represents about $10 \%$ tend to diversify their activities. Oxen users who are between the ages 50-59 years represent $3.3 \%$ as many completely abandoned AT technology as they grow older.

To a grass-field man, family union is part of their ancestral heritage as $97.8 \%$ of oxen-farmers were married while $2.2 \%$ revealed to be single.

The highest number of household ranges from 5-9 persons with a percentage of 47.8 and households below five (05) represent about 38.9\% and just few farmers are having more than ten (10) persons with a percentage of 13.3, (Table 2). Household size determines the labour means and the future level of animal traction adoption.

This study shows that information seekers (Innovators) are the minority and the most educated as $4.40 \%$ are those that attained secondary level of education. Most of these innovators are those that acquired training from PAFSAT. Those of primary level constitute about $82.20 \%$ of the population, and only $4.40 \%$ attended secondary level (Figure 2). Most parents preferred carrying out personal activities (agriculture, trades and other handworks) with their children than sending them to school. This accounts for the low level of education in the Upper Noun Valley.

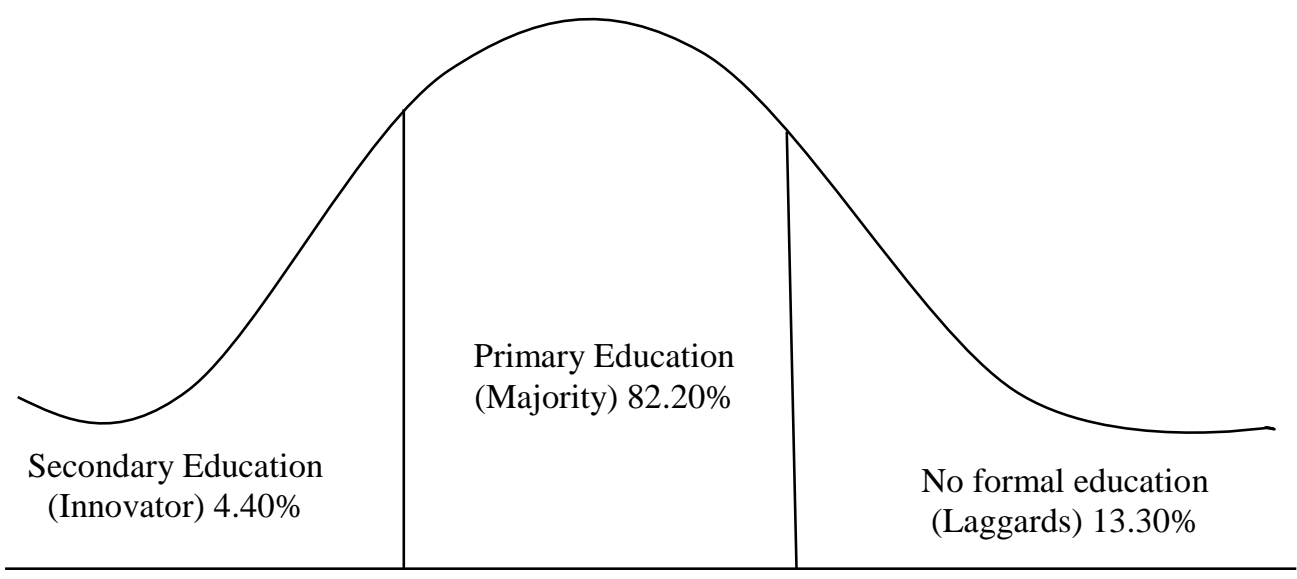

Figure 2: Level of education and degree of at adoption by farmers in the upper noun valley

Table 3: Formal training

\begin{tabular}{lcc}
\hline & Frequency & Percentages \\
\hline Yes, trained by PAFSAT & 05 & 5.6 \\
No, working experience & 85 & 94.4 \\
Total & 90 & 100 \\
\hline
\end{tabular}


During the pilot phase of PAFSAT, famers were trained and empowered but they later disengaged themselves from animal traction practices and did not fully transmit the technology as $94.4 \%$ of the oxen-farmer today in the UNV has no formal training. This is because some of the trained farmers were sceptical and believed that, for any organisation to bring an innovation, it is all in the interest of that organisation. This accounts for less transmission of AT technology and poor management on the path of the farmers and the then PAFSAT staffs or field agents. These farmers are left to develop their indigenous knowledge (Joubert and Kotsokoane, 1999).

\section{COMPARATIVE EFFICIENCY OF ANIMAL TRACTION MECHANISTION}

Both animal traction and tractor are agricultural technologies geared towards agricultural development and sustainability. These technologies aimed at increasing agricultural output and to ensure food security in the country and in order to ensure this food security, some of the farmers in the Upper Noun Valley do not only practice agriculture but diversify their activities. Away from farming, some do trades and transportation (bike riding), mostly the youth. Those singly involved in agriculture is about $87.8 \%$ and about $12.2 \%$ of the sampled population combine agriculture with other activities as indicated in Figure 3. This diversification can be because of land fragmentation that limits farmers from cultivating on bigger scales that can help sustain their lives. Diversification of activities by the farmers brings doubt to AT profitability (Starkey, 1994).

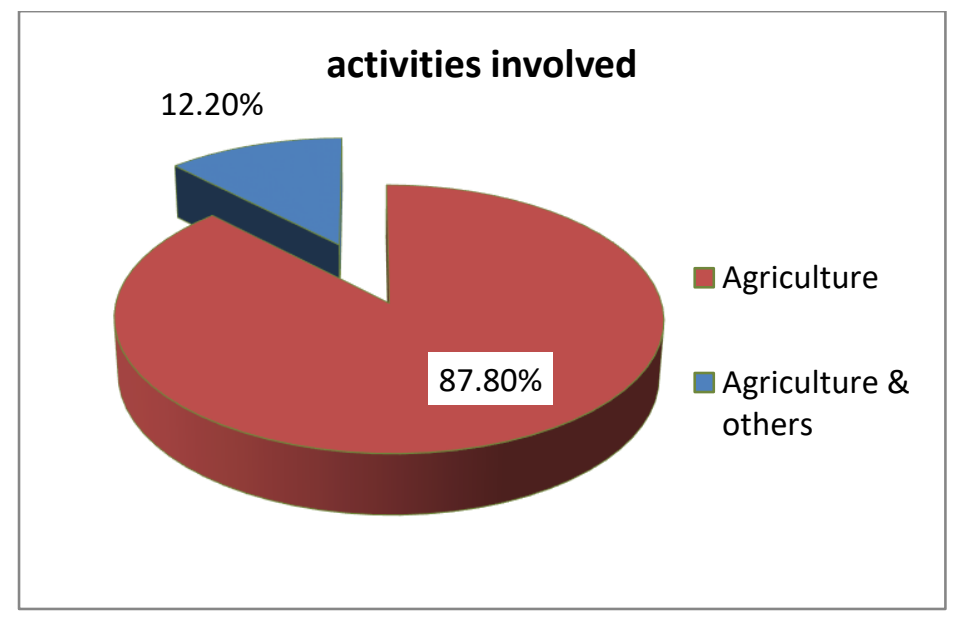

Figure 3: Activities Involved

\subsection{A Reduced-cost of mechanised farm power}

In Sub-Saharan Africa, about 55\% of the rural people is said to be living below the poverty line (IMF, 2010). Therefore, it will be efficient for a small-scale farmer to operate with animal-draft than buying or hiring a tractor since it is cheaper buying a pair of work-oxen. Hiring a tractor by a farmer would not bring in any extra benefit unlike owning a pair of oxen and selling them at an appreciated rate.

With the current trend of agricultural mechanisation and modernisation, the people of Upper Noun Valley are of the view to mechanise their agricultural sector and to increase the cultivated areas and yields. Animal traction is an affordable and an easy technology to most common farmers in this region. Animal traction as a reduced-cost of a mechanised farm power greatly attracts these farmers to adopt the technology. 


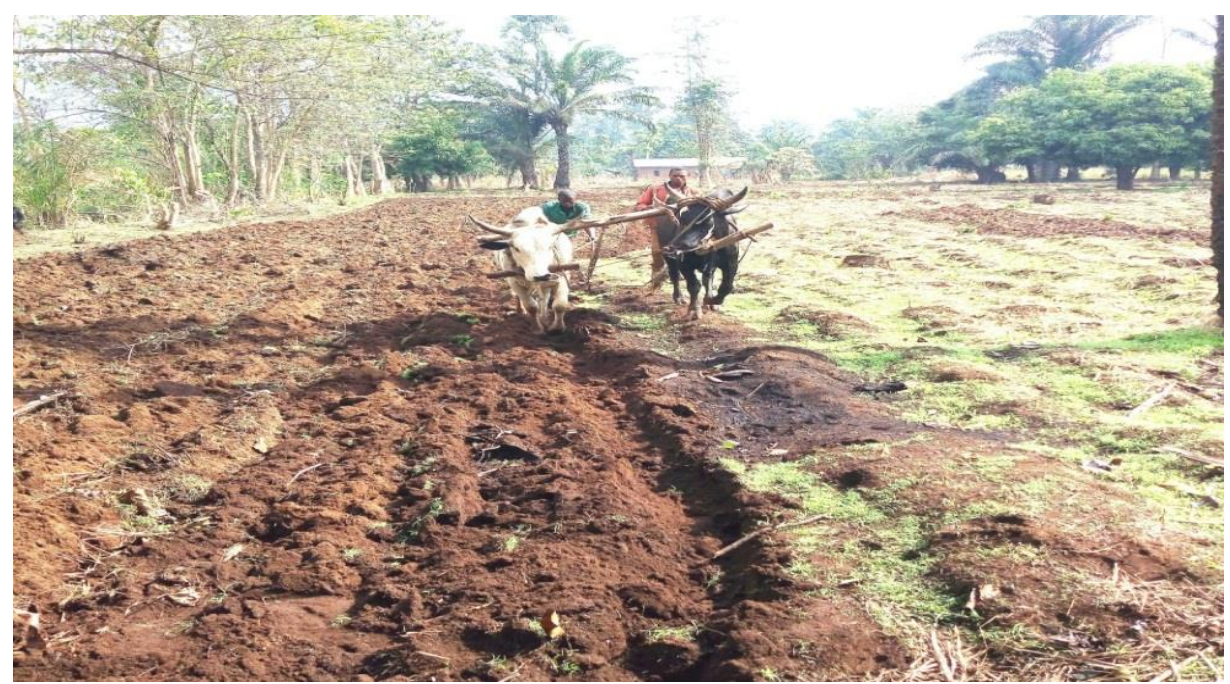

\section{Plate 1: Animal traction mechanisation in practice}

\subsection{Timeliness}

In the UNV, about $93.3 \%$ of the farmer owns the animals (Figure 4). The affordability and availability of animal-draft improves timeliness of ploughing unlike the infrequent tractors for the farmers. Cultivating at an appropriate time guarantees good yields. Therefore, animal traction is more appropriate and efficient than tractors on small-scale farms.

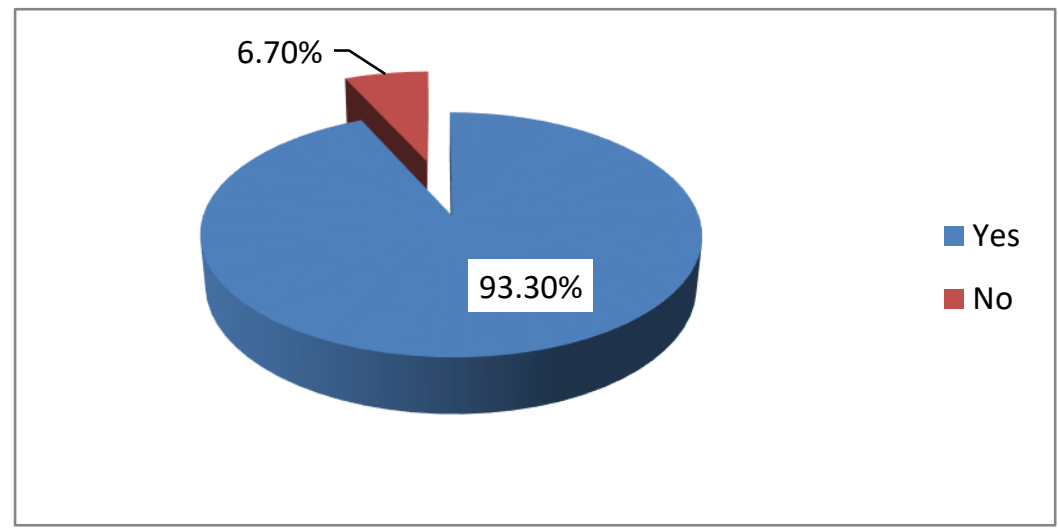

\section{Figure 4: Oxen ownership}

\subsection{Flexibility}

In the Upper Noun Valley, most of the farmers use animal traction for the cultivation of rice. Rice cultivation usually starts in the month of July and often in fragmented swamps. This has favoured the use of draft-animals than a tractor. The flexible nature of animal traction technology has made penetration in to the interiors possible and even in bad weathers. The advantage here is that animals cannot sink unlike tractors that often stock-still in swamps. This has helped to increase the cultivated areas for small scale farmers, eased evacuation of goods from interior and in bad weather conditions especially in places where cars cannot drive. Its flexibility has gone to increase farmers' cultivating surfaces and increases in yields.

\subsection{Additional source of manure from crop-livestock integration}

Animal traction practice encourages crop-livestock integration as most farmers in the Upper Noun Valley today provide their fallowed farmland for herdsmen to keep their animals in order to improve 
their fertility as dungs are being dumped on the farm. Animal traction does not only increase soil fertility and yields but has come to reduce the problem of farmer-grazer conflicts.

\subsection{Off-farm income source}

Animal traction package comes with the possibility of income generation through off-farm transportation and hiring. A farmer who offers off-farm services gets extra rewards. It is difficult for farmers to produce all what they want, therefore, off-farm incomes helps them secure their food needs through purchase.

\subsection{Yields increase and labour savings}

The use of animal traction has the potential to increase yields with horizontal and vertical agricultural development through improving water infiltration, seed-bed preparation (Eisa, 2015). Most farmers in the Upper Noun Valley complained that with tractorisation, ploughing and harrowing are not always soft enough to encourage fertility as experience has proven that with animal traction, ploughing and harrowing soften the soil than a tractor. Affordability of animal power has the advantage to increase a small-scale farmer's yields since he or she is able to cultivate on time rather than waiting for tractors which hardly come at the expected time.

\section{CONSTRAINTS TO ANIMAL TRACTION (AT) DEVELOPMENT AND SUSTAINABILITY}

Despite all the advantages and benefits involve in the use of AT, farmers in the Upper Noun Valley still experience some challenges which they attributed to the following:

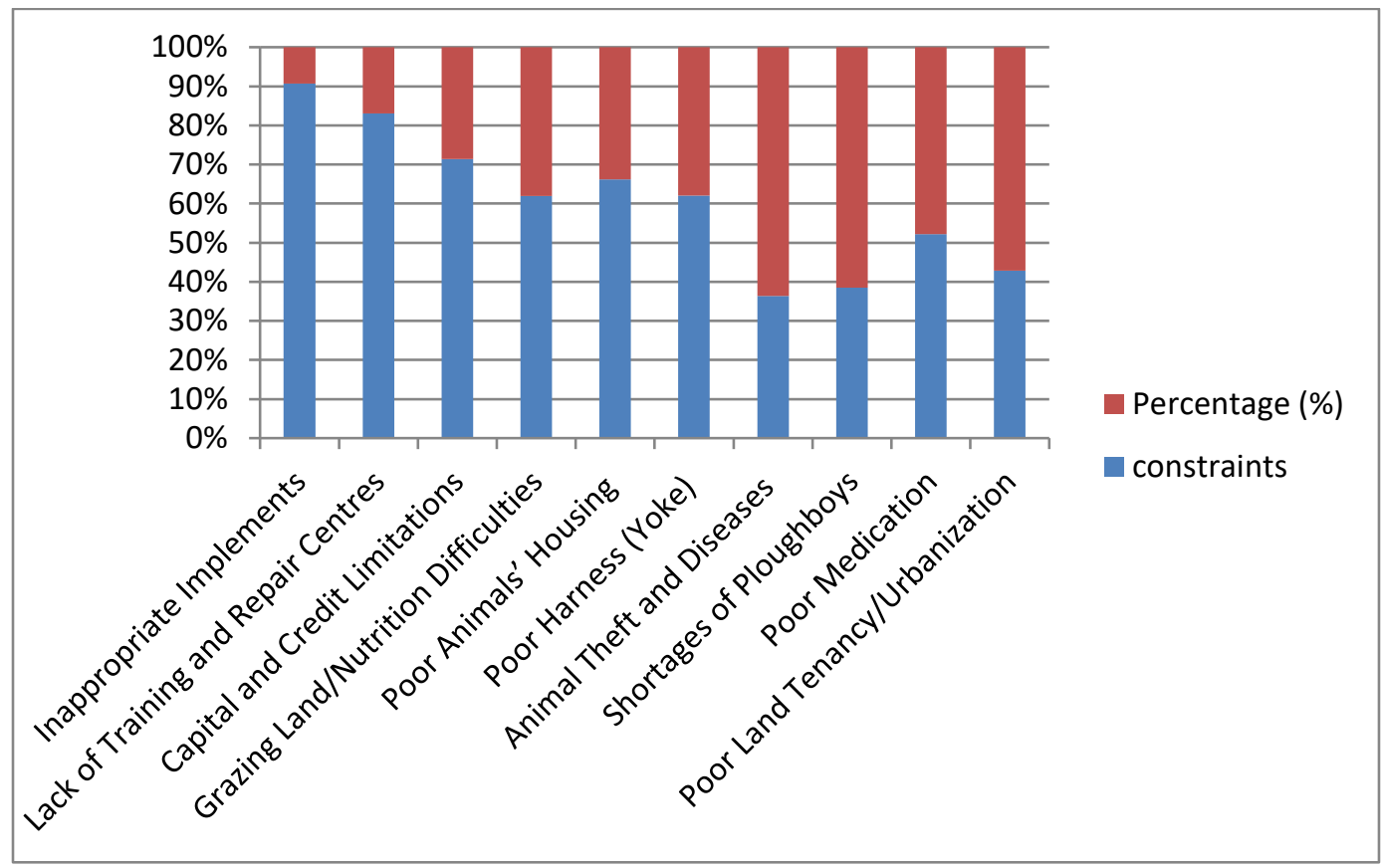

Figure 5: Constraints to animal traction development and sustainability

\subsection{Lack of training and repair centres (limited working knowledge)}

Among the oxen-farmers in the UNV, only about 5.6\% had formal training (Table 3). PAFSAT was the sole body in charged of training and provision of implements to these farmers. With the gradual disengagement of PAFSAT, it has greatly hinders the farmers' knowledge in the technology as majority find it difficult to detect when their animals are sick, getting spare parts is also a challenge 
as there are no training and repair centres in the locality. This has caused the recurrent abandonment of implements. Most of the farmers travel long distances to Bamenda for repairs due to the absence of blacksmiths in the region and the few welders do not have knowledge in designing or repairing these implements which to them is a risk and time consuming as they could have taken the time to concentrate on their activities.

In addition to the problem of implements and spare parts, most agricultural training institutions in the country, impact very little or no information on animal traction unto the trainees (future frontline agricultural extension staff). This makes close follow up and technical assistance of oxen farmers difficult because there is only one Subject Matter Technician (SMT) per Division in five of the seven Divisions of the North West Region who are staff of the North West Development Authority (MIDENO from its French acronym). Some of these SMTs are already approaching retirement as they were those trained by the German experts before handing the Project to the Cameroon Government in the eighties (Ngeh et al., 2015)

One of the challenges farmers face in putting draft animals for farming today is the lack of general knowledge about farming with animals. Poor implement adjustment causes unnecessary work for animals and farmers. The lack of knowledge due to inadequate training is responsible for the poor use of implements which reduces the overall efficiency of animal draft-cultivation. This is a crucial constraint to animal traction as in extreme cases, the difficulties experienced has led to the abandonment of this technology in parts of the area like the case of Bamunka with $1.1 \%$ level of adoption (Table 1). Kline and Le Moigne reviewed and concluded that AT adoption in Africa was limited due to inadequate extension and support services, (Kline et al., 1970; Le Moigne, 1978).

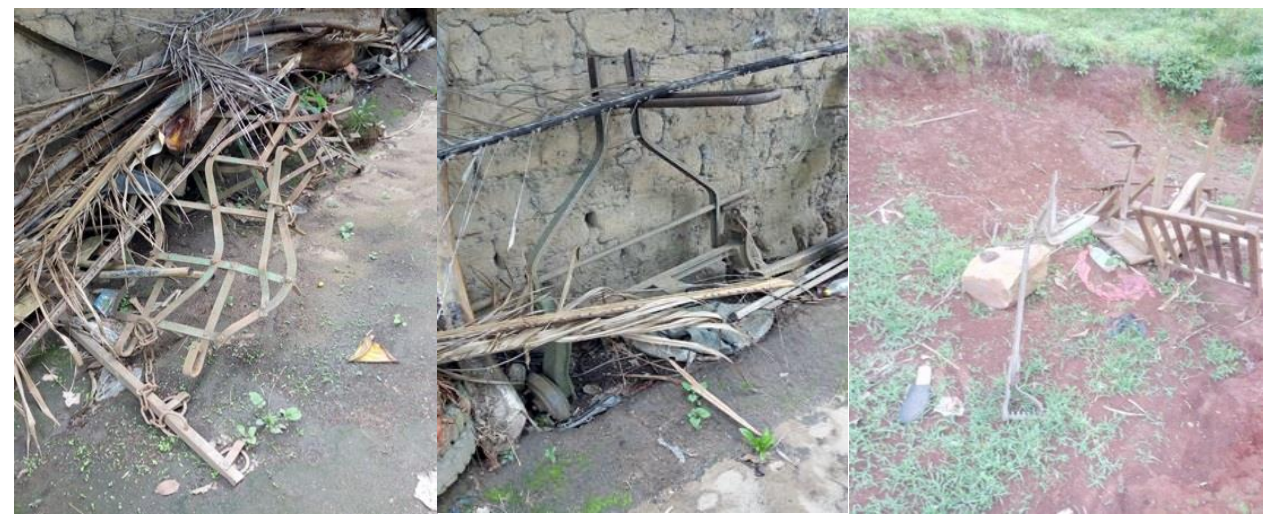

\section{Plate 2: Abandoned implements in Bamunka}

\subsection{Capital and credit limitations}

Capital or credit limitation is a constraint to agricultural development. The adoption of animal traction technology highly depends on the availability of capital or credit facility. This limitation has greatly limited the number of oxen adopters in the UNV. Lhoste and Havard concluded that most States had disengaged from development because of their financial difficulties and pressures exerted by the international financial community (Lhoste, 1995; and Havard, 1997). Only 25\% of the farmers have access to credit facility against $75 \%$ with no access (Figure 6). This is a big challenge to AT expansion in the UNV as most of the farmers especially the "non-oxen" adopters complained of financial limitation for acquiring a complete set of work-oxen. None of the farmer has access to agricultural loan, but about $25 \%$ have access to their local savings which to them is marginal to sustain draft-cultivation. This saving only goes to assist them to pay their children fees.

The market costs of oxen, cultivation implements and carts in this area are high in relation to the farmers' income level which are low as $55 \%$ of the rural people live below the poverty line (IMF, 
2010). In areas of low animal traction adoption, few crop farmers have both sufficient savings and also the confidence in animal traction to purchase animals and implements without assistance. This has greatly limits the evolution of animal-draft technology in the area.

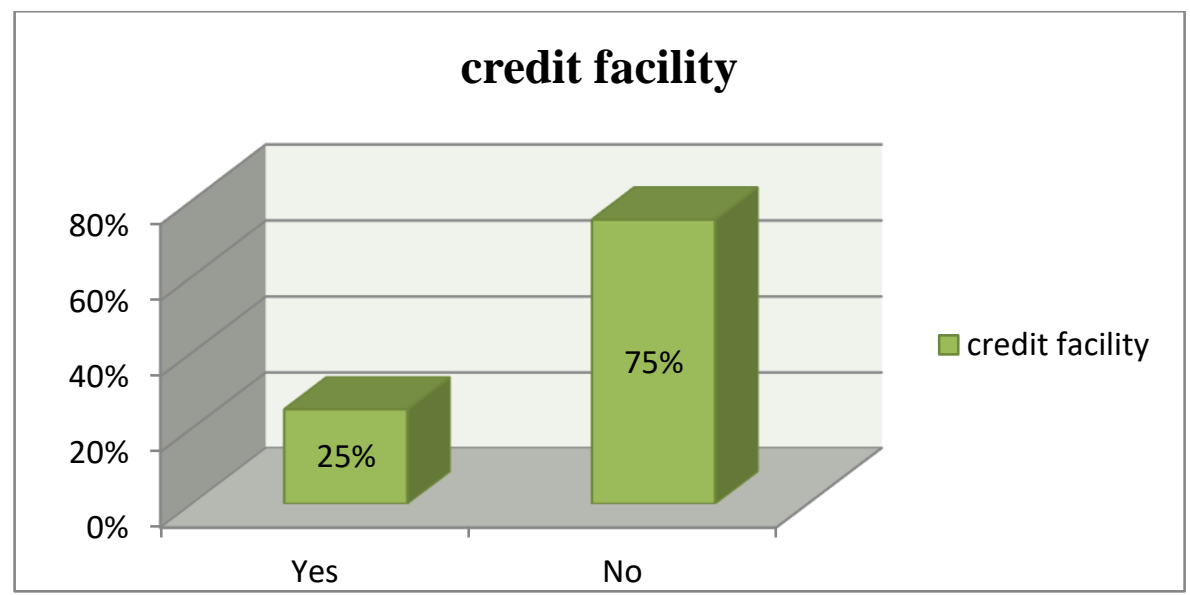

Figure 6: Credit Facility

\subsection{Grazing land/nutrition difficulties}

Inadequate animal nutrition is often cited as a major constraint to the use of animal traction (Sangaré, 1988). Animals are expected to cultivate fields at the beginning of the rainy season. This is the very time of the year when they are in poorest condition, following the inevitable weight losses of the dry season.

In the Upper Noun Valley, land tenancy greatly disfavour smallholder farmers as most of the lands are in the hands of the State or traditional authorities. Added to this, population pressure on land from urbanisation, oxen-farmers in the region find it difficult to freely graze their cattle around. They often confine their cattle on spotted areas with little or poor pasture (Plate 3). Unlike the case in Sierra Leone where farmer-grazier conflict is recurrent between farmers as they are forced to graze their animal on the limited grazing land. With this nutrition difficulty, the draft animals at times encroach into farmland. Some farmers reported that they had to pay out significant sums in compensation as a result of the alleged misbehaviour of their work oxen (Corbel, 1988).

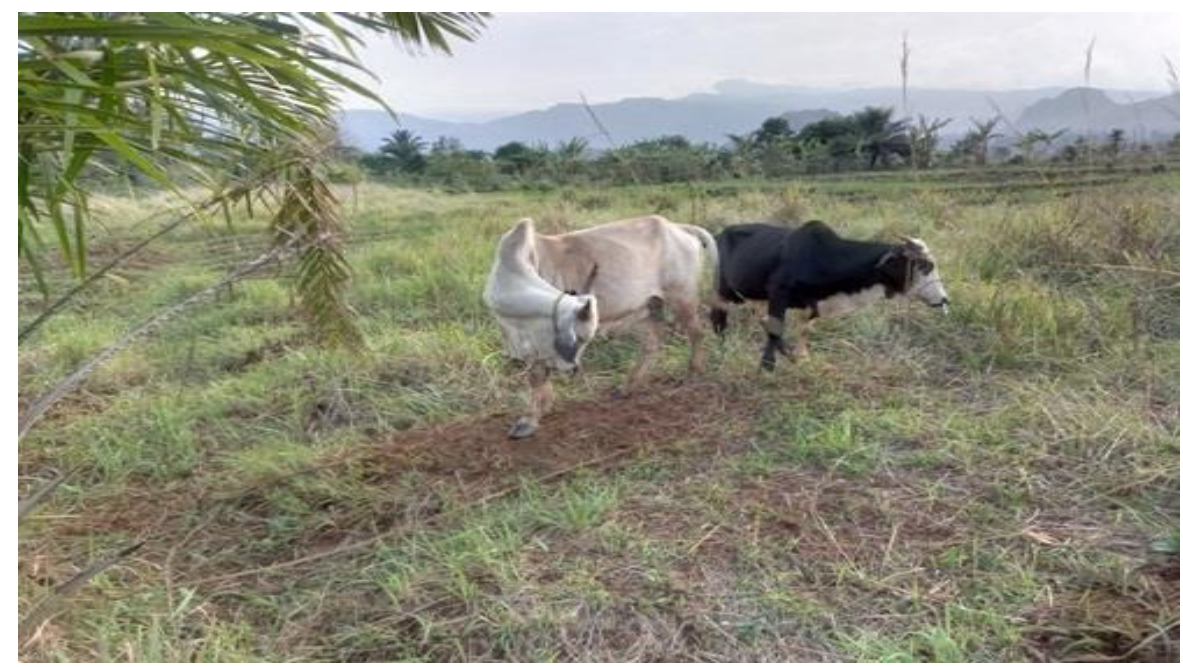

Plate 3: Grazing land/nutrition difficulties 


\subsection{Poor animal housing}

With regard to housing, the animals are often poorly housed and exposed to several risks including theft and infections. Throughout the farming season, owners or farmers keep their draft animals in open spaces within their compounds. Within the communities, the existed fences are poorly constructed with no shade and these animals suffered from rain and sun effect both in rainy and dry seasons respectively.

Away from the risks involving the animals, the animals are loose and freely move away from their habitat at will. This has caused most of the farmers to have continuous sleepless nights as they take guard of the animals. A farmer in Bamessing narrates:

“...I have a good house and a good bed, but I don't know how it looks like at night because I stay outside with my animals because of thieves...' (Respondent, 2018)
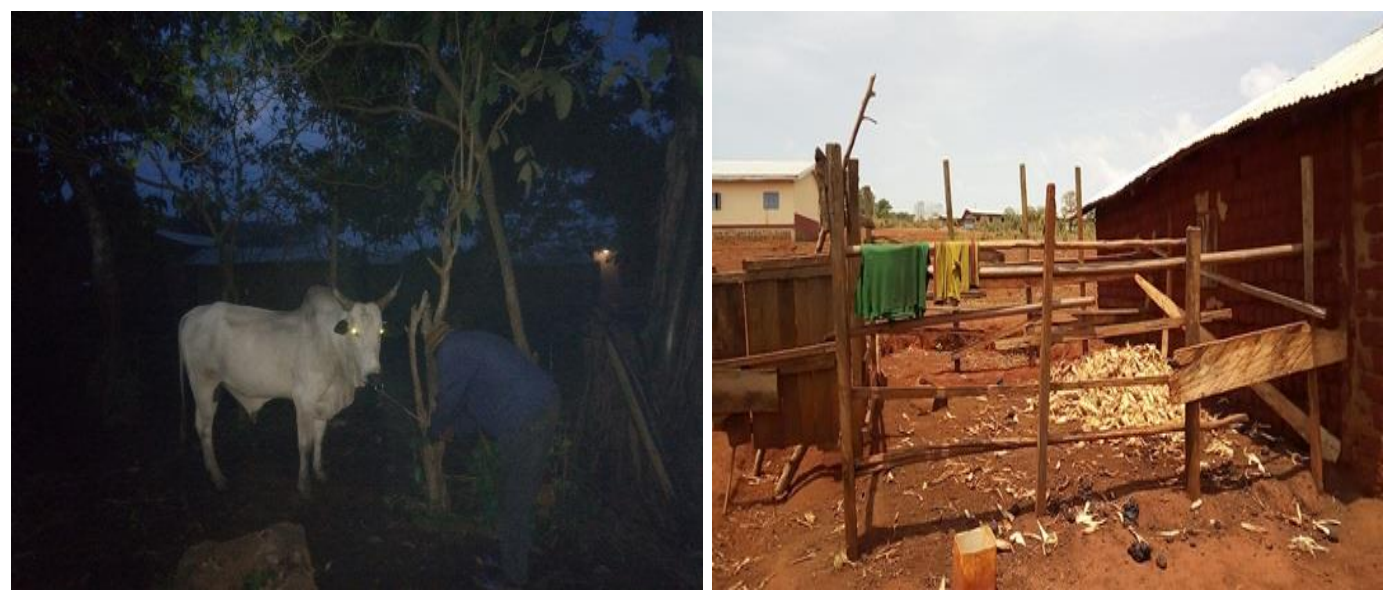

Plate 4: Poor shades for the animals

\subsection{Poor harness (Yoke)}

Regarding inappropriate nature of implements, the current weaken yokes made from wooden poles or planks and the traditional collar harness are uncomfortable to the animals. The yokes' points of contacts are so small that the pressure developed causes harness blisters and restricts the animals during work as (Plate 5).
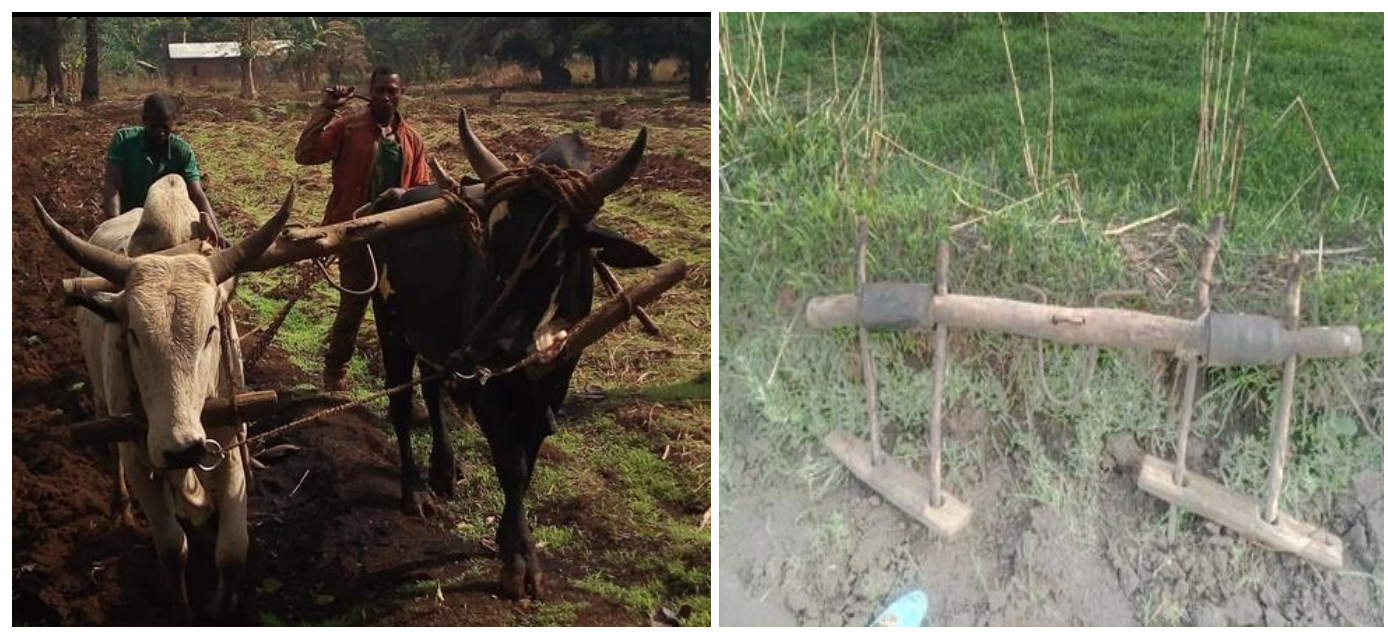

Plate 5: Poorly harnessed yoke 


\subsection{Animal theft and diseases}

Rampant thefts and prevalence of diseases are other key constraints to animal traction. This is highly caused by lack of shades, controlled grazing land and animals' exposure to rain and sun throughout the seasons. Moreover, state interest in animal traction technology as part of the country's agricultural mechanization strategy is limited, as seen by the abandonment of former training centres (PAFSAT), lack of veterinary centres in the community.

\subsection{Shortages of ploughboys}

The current increase rate in school enrolment in the Upper Noun Valley saw a reduction in services rendered by the youth as ploughboys. Animal traction farming in Ngoketunjia has in the past relied largely on young boys to guide the animals in the field. The future of animal traction sustainability depends on its level of transmission.

\subsection{Extension or veterinary service}

In the Upper Noun Valley community, there are no extension and veterinary services. This has greatly limits the progress of animal traction as local farmers practice auto-medication which at time cause harm than good to the animals.

\subsection{Poor medication}

Field survey shows that there are no veterinary and extension services available for oxen-farmers in this area, this has led to poor adaptation, poor animal health and even death of cattle. The negligence of stakeholders (many think animal traction is an old technology) is a course for neither a veterinary nor an extension services directed towards animal traction. Farmers using animal traction have been left on their own and agricultural extension workers currently do not receive training in draught animal technologies (Starkey, 1995).

\subsection{Poor land tenancy}

Most of the lands in this region are in the hands of the government, traditional authorities and some well-to-do individuals. Majority of land owners here are not interested in agriculture, most of the lands are occupied and kept unexploited, making it difficult to those willing to exploit the land. Most of the farmers in Ngoketunjia are not wealthy enough to afford for permanent plots as UNVDA controls most of the cultivable land in the locality.

\section{CONCLUSION AND RECOMENADATION}

The timeliness and flexibility of animal traction has proven its effectiveness on smallholder farms as most oxen owners are able to cultivate at the appropriate farming period. With the unpredicted climatic variability, timing in agriculture today plays a key role in productivity. Animal traction affordability increases agricultural productivity. The majority of the farmers are of low educational background with about $82.20 \%$ as primary dropped-out. Given their level of education, majority are still able to operate the technology. The efficiency and profitability of animal traction is a reality as it is environmental friendly to small-scale farming. The low adoption of AT in this area is largely attributed to challenges like; inappropriate implements where about $90 \%$ complained of, repair and training centres, lack of extension and veterinary services, grazing problem, limited credit facilities, poor shades for the animals, theft and urbanisation. Considering the necessity of identifying and responding to the present and future challenges of food security, there is the need to collaborate and harmonise the agricultural sector by providing strategies for agricultural mechanisation in order to achieve food security where animal traction is one of the solutions to increase agricultural production.

To expand animal traction and to make it sustainable, there is the need to regain consciousness on abandoned training centres, assisting local blacksmiths

$>$ To overcome scepticism, farmers should diversify their crop production 
More ploughboys should be trained. Despite higher rate of school enrolment, these boys can still assist in feeding the animals or in transportation from time-to-time.

$>$ The government should invest in research on animal traction in order to help develop the sector towards agricultural sustainability and scale up the adoption and efficient in the use of animal traction technology.

Affordable agricultural loans should be assured to the oxen-farmers by the stakeholders.

$>$ The government should ensure the provision of seed varieties farmers in order to overcome their sceptical nature

Funding: This study received no specific financial support.

Competing Interests: No conflict of interest was reported by the authors.

Contributors/Acknowledgement: All authors participated equally in designing and estimation of current research.

Views and opinions expressed in this study are the views and opinions of the authors, Asian Journal of Agriculture and Rural Development shall not be responsible or answerable for any loss, damage or liability etc. caused in relation to/arising out of the use of the content.

\section{Reference}

Corbel, H. (1988). The economics of animal power in koinadugu district, Sierra Leone. A Case Study of the work oxen introduction and credit programme. pp. 299-310. view at Google scholar

DDARD/Ng (2017). Divisional Delegation for Agriculture and Rural Development for Ngoketunjia. Annual Report, 2017. Government of Cameroon.

Eisa, A. (2015). Role of animal traction in agricultural development in Zalingei area, Darfur-Sudan. 2 College of Engineering, University of Khartoum, 11115, Khartoum, Sudan. Veterinaria, 3(1), 22-27. view at Google scholar

Everett, R. (1971). Diffusion of innovations. Rev. ed. of Communication of Innovations. 2nd ed. A Division of Macmillan Publishing Co., Inc New York \& Collier Macmillan Canada. view at Google scholar

Havard, M. (1997). Assessment of animal traction in French-speaking sub-Saharan Africa. Perspectives and research development. Diploma of advanced studies in agricultural sciences and biological ingenesis of the university faculty of agricultural sciences of Gembloux (belgium), $72 \mathrm{p}$.

International Monetary Fund. (2010). Growth and employment strategy paper. Reference Framework for government action over the period 2010-2020. Country Report (10), pp257, Cameroon: Poverty Reduction Strategy Paper.

Johnston, B. F., \& Mellor, J. W. (2007). The role of agriculture in economic Development. AgEcon, Rev, 51, 566-563. view at Google scholar

Joubert, B., \& Kotsokoane, J. (1999). Empowering farmers with animal traction. Worldwide Trends, Issues and Challenges, in Starkey, P. (ed). Empowering Farmers with Animal Traction: Mpumalanga: ATNESA.

Kline, C., Green, D., Donahue, R., \& Stont, B. (1970). Agricultural mechanisation in equatorial Africa. Institute of International Agriculture Research Report n ${ }^{\circ}$ 6. Michigan State University, East Lansing, Michigan, USA. view at Google scholar

Le Moigne, M. (1978). Attached culture in French-speaking Africa. Center for Education and Experimentation in Agricultural Machinery, Antony, France.

Lhoste, P. (1995). Animal traction in Africa. Situation and prospects. Communication at the meeting of the working group. FAO / CIHEAM on animal traction, 15-16 December 1995, Zaragoza (Spain), 14 p. view at Google scholar

MIDENO (2010). Mission de Development du Nord Ouest Report on the Animal Traction Training in the North West Region under Grassfield Particpatory and Decentralised Rural Development Project. 
Nazaire, H., Shashidhara, K., Bobobee, E., \& Owusu, V. (2015). Animal traction potential and constraints. International food policy research institute (IFPRI) Washington D.C., USA. P1415. www.rural21.com.

Ngeh, M. N., Manu, I. N., Tohnain, N., Tarla, D. N., Muluh, G. N., \& Fon, D. E. (2015). Socioeconomic Effects of Animal Traction on Agricultural Development in the North West Region of Cameroon. (University of Dschang) http://www.landmarkresearchjournals.org/lrjass/home.

Njei, M. (1987). The impact of animal traction for production in a permanent farming system in north-west Cameroon. The Role of the PAFSAT Project. Accessed on: February 21, 2018. Available at: http://www.fao.org/wairdocs/ilri/x5455b/x5455b25.htm.

Rušarovȧ, K., Mazancová, J., \& Harvrland, B. (2016). Factors limiting adoption of technologies by farmers in catabola municipality, Angola. Accessed on the 19 September 2018. view at Google scholar / view at publisher

Sangaré, A. (1988). Constraints and improvements in animal traction in Mali-sud: the experience of the DRSPR pp. 191-211. in: P.H. Starkey and F. Ndiamé (eds), Animal power in farming systems. Proceedings of networkshop held 17-26 September 1986 in Freetown, Sierra Leone. Vieweg for German Appropriate Technology Exchange, GTZ, Eschborn, Federal Republic of Germany. 363p. (E/F). (check for removal).

Starkey, P. (1994). A world-wide view of animal traction highlighting some key issues in eastern and southern Africa. Improving animal traction technology. CTA, mills litho, Maitland, cape town, South Africa, 146-149. view at Google scholar

Starkey, P. (1995). The Donkey in South Africa. Myths and Misconceptions, in Starkey, P. 2000. Animal Traction in South Africa, Empowering rural communities: Harare: ATNESA.

Umaru, M., Dalhatu, M, Bello, A., \& Nawawi, H. (2013). Animal traction as source of farm power in rural areas of Sokoto State, Nigeria. Health, safety and environment. Accessed on September $19^{\text {th }} 2018$ available at; http://sjournals.net/ojs.

Walter, O., Denis, M., Ewan, T., Susan, C., Charles, W., \& Alexandra, P. (2015). Contribution of Draft Cattle to Rural Livelihoods in a District of Southeastern Uganda Endemic for bovinparasitic diseases: an Economic Evaluation. National Center for Biotechnology Information, U.S. National Library of medicine.8600 Rockville Pike, Bethesda MD, 20894 USA. view at Google scholar / view at publisher 